\title{
Management of children and adolescents having type 1 diabetes during COVID-19 pandemic in India: challenges and solutions
}

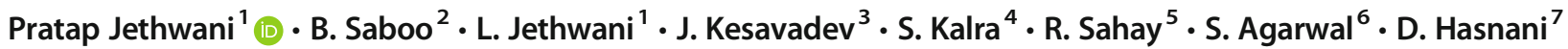

Received: 24 June 2020 / Accepted: 19 August 2020 / Published online: 15 September 2020

(C) Research Society for Study of Diabetes in India 2020

\begin{abstract}
Purpose Type 1 diabetes (T1D) requires a holistic approach and continuous care. The current COVID-19 pandemic has made the health care professionals realise its challenges even more ardently than in the normal times. In a country like India with its huge population burden and a significant number of people having T1D, the risk of COVID-19 in people having T1DM is considerably high.

Methods In this article, we are sharing our practical experiences of problems faced by children and adolescents having T1DM during the past 2 months of lockdown.

Results We have classified the challenges into 3 broad categories based on diabetes self-management, healthcare system and psychosocial aspects. We have tried to provide precise, comprehensive and region specific solutions to these challenges. Solutions briefly include maintaining the supply chain of essentials like insulin, syringes and glucose meter strips to psychological support, financial aid and support for hospitalization in case of COVID-19 itself or diabetes complications including diabetic ketoacidosis.

Conclusions Children and adolescents having T1DM require special care and attention during this period of COVID-19 pandemic because of various challenges as discussed. Our proposed solutions may help them overcome these problems and help them in better diabetes management during such emergency situations.
\end{abstract}

Keywords Type 1 diabetes $\cdot$ COVID-19 $\cdot$ Challenges $\cdot$ Solutions

\section{Introduction}

As per IDF, there are estimated 1.1 million children and adolescents having type 1 diabetes (T1DM) globally [1]. India was home to 95,600 T1DM between 0 and 14 years of age

Pratap Jethwani

pratapjethwani2001@yahoo.co.in; pratapjethwani@gmail.com

Jethwani Hospital, 5-Junction Plot, Rajkot-1, India

Diacare-Diabetes Care \& Hormone Clinic, Ahmedabad, India

3 Jothydev's Diabetes Research Center, Thiruvananthapuram, India

4 Department of Endocrinology, Bharati Hospital, Karnal, India

5 Department of Endocrinology, Osmania Medical College, Hyderabad, India

6 Department of Medicine, Ruby Hall Clinic, Pune, India

7 Diabetes Care Clinic, Ahmedabad, India in 2019 and about 15,900 new cases diagnosed every year in the same age group [1].

Currently, mankind is facing a global pandemic of COVID-19, caused by the severe acute respiratory syndrome coronavirus 2 (SARS-CoV-2) infection [2], with 18,575,326 people infected in more than 200 countries and 7,01,754 people who have died, as per the WHO as of 6 August 2020 [3]. The Indian numbers have now risen to 19,64,536 total reported positive cases and 40,699 deaths [4].

\section{Type 1 diabetes and COVID-19}

A recent study (currently under peer review) from England demonstrated an independent association between the level of glycemia and COVID-19 mortality in people having T1DM or type 2 diabetes [5]. Another NHS-funded population cohort study reported 3.5 times more risk of in-hospital deaths with COVID-19 in people having T1DM as compared with those without diabetes [6]. The gaps in pediatric diabetes 
management can be bridged with the use of telemedicine, virtual diabetes clinics, and diabetes technology in the current COVID-19 situation [7].

As there is no definitive treatment or preventive vaccine for this viral infection, personal hand hygiene, respiratory etiquette, and social distancing are the most widely used strategies for the control of this highly contagious virus. Outbreak control measures to reduce the amount of mixing in the population include work from home, closure of academic organizations, and strict lockdown [8]. For this reason, a nationwide lockdown has been imposed in India from 25 March 2020 up to 30 June 2020 [9]. Lockdown, although effective in curbing the community transmission of this virus, has potential impact on people living with diabetes, particularly T1DM. We intend to enumerate the challenges being faced by the children and adolescents having T1DM and some solutions that have been proposed and worked out.

These challenges can be broadly divided into 3 categories as shown in Table 1.

\section{Challenges related to diabetes self-management (DSM)}

Skills of DSM are essential for children and adolescents having T1DM to improve or maintain glycemic control, to improve quality of life, and to minimize the risk of complications $[10,11]$. For people living with T1DM, DSM includes regular insulin injections with proper technique, regular blood glucose monitoring, healthy eating, physical activity, problem-solving, and healthy coping [10]. Current situation of lockdown has had an impact on many components of DSM as described below.

Table 1 Classification of challenges faced by children and adolescents having T1DM during lockdown

(1) Challenges related to diabetes self-management (DSM)

(i) Insulin therapy

(ii) Glucose monitoring

(iii) Medical nutrition therapy

(iv) Physical activity

(v) Sick day management

(vi) Emergency preparedness

(2) Challenges related to healthcare system

(i) Routine healthcare support/medical specialist support

(ii) Emergency issues related to glucose control—hypoglycemia, DKA

(iii) Emergency issues related to COVID-19

(iv) Technical issues

(3) Challenges related to psychosocial aspects

(i) Psychological issues

(ii) Financial issues (i) Insulin therapy: It is essential for survival in all people with T1DM. Children and adolescents with T1DM require multiple daily insulin injections (1-2 basal insulin injections plus at least 3 regular or rapid acting insulin injections) as per recommendation by the major organizations [12-14]. Many of these children and adolescents are supported by various programs (like Changing Diabetes in Children (CDiC) and Life for a child program) for regular supply of insulin and glucose meter strips [14]. This is being facilitated by local healthcare teams. Because of lockdown, many children residing in remote villages may not get regular insulin supplies because of closure of nodal healthcare facilities and local transport facilities.

Proposed solutions: Children and adolescents having T1DM should be able to reach nodal persons of supporting programs in case of inability to get insulin vials or cartridges. The Research Society of Study of Diabetes in India (RSSDI) has circulated the contact numbers of nodal persons of insulin manufacturers and supporting programs to people having T1DM and their doctors through email and social media. A dedicated helpline number, supported by diabetes educators and medical specialists, should be available to provide solutions to day-to-day problems. Unavailability of any type of insulin may require switching to another type so as to avoid risk of hyperglycemia and consequent DKA. One of the approved protocols suggests 20\% reduction in insulin dose during switch from rapid acting insulin analogue to regular human insulin or vice versa to avoid hypoglycemia [15].

(ii) Glucose monitoring: Regular self-monitoring of blood glucose and continuous glucose monitoring at times is an essential component of T1DM management [16]. Lockdown may interrupt regular supplies of glucose meter strips to children and adolescents, being supported by programs like $\mathrm{CDiC}$, because of closure of local nodal centers and local transport facilities.

Proposed solutions: RSSDI has circulated a list of contact numbers of nodal persons of glucose meter manufacturers and urine ketone strips to people having T1DM and doctors through email and social media.

(iii) Medical nutrition therapy: Because of strict lockdown and suspension of even vegetable supplies in certain areas, children and adolescents may not get regular supply of vegetables and fruits, an important component of their healthy eating plan [17]. There may be reduction in eating outside and consumption of junk foods because of lockdown, and this will probably have an impact on insulin requirements. However, no definite data related to this issue is available. 
Proposed solutions: Local support groups like Juvenile Diabetes Foundation (JDF), in collaboration with local health authorities, should arrange for regular supply of milk, vegetables, fruits, and other essentials to these children and adolescents. Information booklets and animated videos related to healthy eating and healthy recipes may also be circulated through digital media.

(iv) Physical activity: Because of lockdown and stay at home orders, children and adolescents may not be able to participate in daily sports and playground activities [13] that may worsen their glycemic control.

Proposed solutions: Children and adolescents with T1DM should be encouraged to do indoor exercises by educating them through online tools as well as through social media. Because of closure of schools and colleges, they may get more time and should be encouraged for indoor physical activities. Use of animated videos featuring cartoon characters may prove useful in motivating children for indoor plays and exercises. Local support groups may also provide peer support for the same.

(v) Sick day management: During periods of stress and acute infections, reduced oral intake and increased release of stress hormones may impact blood glucose levels, thereby increasing the risk of both hyperglycemia and hypoglycemia [13]. Therefore, sick day management is particularly useful to avoid glycemic fluctuations and subsequent risk of DKA or hypoglycemia [18]. Lack of continuous insulin supply with lack of glucose monitoring may also increase the risk of hypo- or hyperglycemia.

Proposed solutions: Every child and adolescent with T1DM should be educated about sick day management rules at frequent intervals during lockdown with the help of information booklets and videos through social and digital media. These should be prepared in English, Hindi, and also local languages. Dedicated customer care helpline may assist them in better T1DM management during sick days, thereby reducing the risk of DKA and subsequent hospitalization.

(vi) Emergency preparedness: Emergency preparedness of T1DM children and adolescents and their families are very much lacking in our country. Any emergency situation like the current COVID-19 epidemic, resulting in panic, may worsen their glycemic control with consequent DKA.

Proposed solutions: Emergency preparedness plans can help children and adolescents having T1DM and their families in managing diabetes better during such emergencies. Sample emergency preparedness plan for use during lockdown has been proposed by authors as shown below in Table. 2 .

\section{Challenges related to the healthcare system}

People having T1DM require continuous access to healthcare services. Lockdown may impact the access to healthcare services for their day-to-day management as well for their emergency issues like hypoglycemia, DKA, or any infection including COVID-19.

(i) Routine healthcare support for T1DM management: Because of lockdown and closure of healthcare services, children and adolescents may find it difficult to get medical support for their day-to-day management of T1DM as well as for management of their complications like diabetic neuropathy, retinopathy, and nephropathy.

Table 2 Emergency preparedness plan for T1DM management during Covid-19

\begin{tabular}{|c|c|c|}
\hline \multicolumn{3}{|c|}{$\begin{array}{l}\text { A Portable, Insulated and waterproof diabetes emergency kit can be prepared, } \\
\text { containing the following items } \\
\text { 1. Keep all documents as mentioned in the green column in your kit. Soft copies or } \\
\text { photos of all documents are to be stored in your mobile and shared with your parents } \\
\text { or spouse or near friends. } \\
\text { 2. Keep all ongoing medication (see yellow column) including insulin and glucose meter } \\
\text { strips with adequate supplies for at least 4-6 week. Always check expiration date on } \\
\text { all medications including insulin injections } \\
\text { 3. Gel packs should be kept inside the freezer and should be added to cooler pack along } \\
\text { with Insulin and unused injectable medications when ready to go. Do not use dry ice } \\
\text { and avoid freezing the insulin. }\end{array}$} \\
\hline Documents & Medications/ supplies & Others (Materials) \\
\hline Identity Card- Adhar card & Insulin vials or cartridges & $\begin{array}{l}\text { Batteries for glucose } \\
\text { meters }\end{array}$ \\
\hline $\begin{array}{l}\text { Latest prescription paper of } \\
\text { treating doctor }\end{array}$ & $\begin{array}{l}\text { Insulin syringes or pen needles } \\
\text { or pump supplies }\end{array}$ & $\begin{array}{l}\text { A cooler pack with } \\
\text { room for } 4 \text { gel packs }\end{array}$ \\
\hline $\begin{array}{l}\text { Latest Reports : HbAlc, } \\
\text { S.Creatinine,Urine ACR, } \\
\text { TSH,Hb,ECG }\end{array}$ & $\begin{array}{l}\text { Other medications if any and } \\
\text { O.T.C Medicines for pain, } \\
\text { fever \& vomiting }\end{array}$ & $\begin{array}{l}\text { Empty plastic bottles or } \\
\text { sharps containers for } \\
\text { syringes, needles \& } \\
\text { lancets }\end{array}$ \\
\hline Health Insurance Card & Glucagon kit & $\begin{array}{l}\text { Hand sanitizer- } \\
\text { at least } 2\end{array}$ \\
\hline $\begin{array}{l}\text { Documents of last } 1 \text { year of } \\
\text { diabetes, documents of allergies, } \\
\text { surgeries or any other medical } \\
\text { illness }\end{array}$ & $\begin{array}{l}\text { Glucose meter with strips (at } \\
\text { least } 100 \text { strips for } 30 \text { days } \\
\text { period) and pricking devices } \\
\text { (lancets) }\end{array}$ & Tissue papers \\
\hline $\begin{array}{l}\text { Contact number of family } \\
\text { physician or child specialist, } \\
\text { diabetes specialist, pharmacist \& } \\
\text { parents }\end{array}$ & $\begin{array}{l}4 \text { gram Glucose tablets (at } \\
\text { least } 20 \text { ) or small juice boxes } \\
\text { or hard candies or small plastic } \\
\text { bottle of honey }\end{array}$ & Alcohol swabs \\
\hline $\begin{array}{l}\text { Customer care number of } \\
\text { manufacturer of Glucose meter } \\
\text { /insulin/ insulin pump }\end{array}$ & $\begin{array}{l}\text { One additional glucose meter } \\
\text { of same company }\end{array}$ & Paper soap or soap \\
\hline
\end{tabular}

HbAlc-Glycated Hemoglobin Alc, Hb- Hemoglobin, S-Serum, $A C R$ - Albumin creatinine ratio, $T S H$ - Thyroid stimulating hormone, ECG - Electrocardiogram, O.T.C-Over the counter

$H b A 1 c$ Glycated hemoglobin A1c, $H b$ hemoglobin, $S$ serum, $A C R$ albumin creatinine ratio, TSH thyroid-stimulating hormone, $E C G$ electrocardiogram, O.T.C over the counter 
Proposed solutions: Telemedicine guidelines, by the Ministry of Health and Family Welfare, Government of India, may be followed to provide medical support to them for issues related to insulin dose adjustment and management of their complications [19]. This may be further improved by creating virtual diabetes clinics providing support of nutritionist, physiotherapist, diabetes educator, podiatrist, as well as specialist services. Similarly, web-based tools may be used to educate them about diabetes self-management including foot care [11].

(ii) Emergency issues related to glucose control: Emergency issues like hypoglycemia or DKA requiring hospitalization may be precipitated by lack of proper DSM, stress, and acute infections in these subjects. During lockdown, there may be difficulties in getting hospitalized mainly in remote areas because of lack of transport facilities and lack of availability of beds in COVID-19 affected areas.

Proposed solutions: Children and adolescents along with their families should be educated frequently through online videos about symptoms and management of hypoglycemia as well as DKA. They should be provided with glucose tablets for emergency management of hypoglycemia and should be repeatedly educated about rule of 15 for hypoglycemia management. In case of emergency conditions requiring hospitalization, local support groups like JDF as well as concerned healthcare providers may assist them in getting hospitalized at the nearest healthcare center by providing ambulance services and local support.

(iii) Emergency issues related to COVID-19 or other infections: Children and adolescents having T1DM may develop COVID-19 or any other infection requiring hospitalization. Infections may also result in glycemic fluctuations and may increase the risk of DKA or hypoglycemia further increasing the chances of hospitalization [18].

Proposed solutions: In case of COVID-19, local health authorities should be immediately informed for testing and admission at dedicated COVID-19 centers with the help of local support groups like JDF. People having T1DM and their families should keep handy all their healthcare records including blood sugar log book for review by hospital team. Local healthcare team should coordinate with the hospital team for better T1DM management.

(iv) Technical issues: People having T1DM require use of technology in the form of glucose meters, pricking devices, insulin pens, as well as insulin pumps for routine management. During lockdown, they may not get support to resolve their technical issues because of unavailability of transport services and skilled personnel. Technology-related problems like pump dysfunction may result in unwanted hyperglycemia with consequent DKA.

Proposed solutions: People having T1DM should be provided with 24/7 technical support either onsite or through telecommunication, for successful use of these devices for insulin therapy as well as for glycemic monitoring.

\section{Challenges related to psychosocial aspects}

Children and adolescents having T1DM are already at risk of psychosocial issues because of the impact of disease on them and their families. This may be further aggravated or precipitated by lockdown.

(i) Psychological problems: Children and adolescents with T1DM because of social stigma and other issues related to T1DM are already prone to psychological problems like anxiety, phobia, etc. [12, 20]. Fear of COVID-19, closure of schools and colleges, and restrictions imposed by strict lockdown may impact their mental health and further increase the risk of psychological problems in them.

Proposed solutions: Local help groups run by JDF along with educational institutions can provide mental support by engaging children and adolescents in online educational and funfilled activities. Yoga and meditation may be taught through online platforms to provide them psychological support. Educational institutions may start routine class work through online platforms to keep them busy and engaged in their studies. Information booklets to clear myths and doubts about COVID-19 may help in reducing fear and anxiety related to this disease.

(ii) Financial problems: Financial problems are the most negative aspect of this extreme lockdown. Children and adolescents of lower as well middle socioeconomic status may be hit very hard by financial problems of their parents. This may be due to salary cut, unemployment, and loss of daily wages making it difficult to follow proper T1DM management for them.

Proposed solutions: These vulnerable families definitely require assistance in the form of free insulin and glucometer strip supplies through programs like CDiC. Organizations like RSSDI and support groups like JDF may employ such parents as educators to provide DSM education to others having T1DM. Donors should be sought for to provide financial assistance to such vulnerable families through social media. 
We can briefly summarize that children and adolescents having T1DM require special care and attention during this period of COVID-19 pandemic because of various issues as discussed above. Proposed solutions in this article may help them overcome these problems and help them in better diabetes management during such emergency situations with reduction in the risk of complications particularly DKA. We need to conduct proper prospective studies to identify the problems faced by children and adolescents with T1DM during lockdown and their impact on glycemic control and complications. This may help us to develop precise solutions to improve T1DM management during such pandemic.

\section{References}

1. International Diabetes Federation. IDF Diabetes Atlas, 9th edition. 2019. http://www.diabetesatlas.org. Accessed on 10 May 2020.

2. Parodi SM, Liu VX. From containment to mitigation of COVID-19 in the US. JAMA. 2020. https://doi.org/10.1001/jama.2020.3882.

3. WHO coronavirus disease dashboard. https://covid19.who.int/ accessed on $24^{\text {th }}$ June 2020.

4. \# IndiaFightsCorona COVID-19 in India, Coronavirus tracker. https://www.mygov.in/covid-19 accessed on 6th August 2020.

5. Holman N, Knighton P, Kar P, O'Keefe J, Curley M, Weaver A et al. Type 1 and Type 2 diabetes and COVID-19 related mortality in England: a cohort study in people with diabetes. https://www. england.nhs.uk/wp-content/uploads/2020/05/Valabhji-COVID-19and-Diabetes-Paper-2-Full-Manuscript.pdf accessed on 24th June 2020

6. Barron E, Bakhai C, Kar P, Weaver A, Bradley D, Ismail H et al. Type 1 and type 2 diabetes and COVID-19 related mortality in England: a whole population study. https://www.england.nhs.uk/ wp-content/uploads/2020/05/valabhji-COVID-19-and-DiabetesPaper-1.pdf accessed on 24th June 2020.

7. Danne T, Limbert C. COVID-19, type 1 diabetes, and technology: why paediatric patients are leading the way. Lancet Diabetes Endocrinol. 2020;8(6):465-7. https://doi.org/10.1016/S22138587(20)30155-8.

8. Prem K, Liu Y, Russell TW, Kucharski AJ, Eggo RM, Davies N, et al. The effect of control strategies to reduce social mixing on outcomes of the COVID-19 epidemic in Wuhan, China: a modelling study. Lancet Public Health. 2020;5(5):e261-70. https://doi. org/10.1016/S2468-2667(20)30073-6.

9. Press Information Bureau, Government of India. Government of India issues orders prescribing lockdown for containment of COVID19 epidemic in the country. https://www.mha.gov.in/sites/ default/files/PR_NationalLockdown_26032020_0.pdf accessed on 15 May 2020.
10. Adu MD, Malabu UH, Malau-Aduli AEO, Malau-Aduli BS. Enablers and barriers to effective diabetes self-management: a multi-national investigation. PLoS One. 2019;14(6):e0217771. https://doi.org/10.1371/journal.pone.0217771.

11. Ayatollahi H, Hasannezhad M, Fard HS, Haghighi MK. Type 1 diabetes self-management: developing a web-based telemedicine application. Health Inf Manag. 2016;45(1):16-26. https://doi.org/ $10.1177 / 1833358316639456$.

12. Danne T, Phillip M, Buckingham BA, Jarosz-Chobot P, Saboo B, Urakami T, et al. ISPAD Clinical Practice Consensus Guidelines 2018: insulin treatment in children and adolescents with diabetes. Pediatr Diabetes. 2018;19(Suppl 27):115-35. https://doi.org/10. 1111/pedi.12718.

13. Chiang JL, Maahs DM, Garvey KC, Hood KK, Laffel LM, Weinzimer SA, et al. Type 1 diabetes in children and adolescents: a position statement by the American Diabetes Association. Diabetes Care. 2018;41(9):2026-44. https://doi.org/10.2337/ dci18-0023.

14. Prasanna Kumar KM, Saboo B, Rao PV, Sarda A, Viswanathan V, Kalra S, et al. Type 1 diabetes: awareness, management and challenges: current scenario in India. Indian J Endocr Metab. 2015;19(Suppl S1):6-8.

15. Switching between insulin products in disaster response situations. Approved by the American Diabetes Association, the Endocrine Society and JDRF - August 2018. https://www.diabetes.org/sites/ default/files/2019-08/switching-between-insulin.pdf accessed on 28 May 2020.

16. DiMeglio LA, Acerini CL, Codner E, Craig ME, Hofer SE, Pillay K, et al. ISPAD Clinical Practice Consensus Guidelines 2018: glycemic control targets and glucose monitoring for children, adolescents, and young adults with diabetes. Pediatr Diabetes. 2018;19(Suppl 27):105-14. https://doi.org/10.1111/pedi.12737.

17. Smart CE, Annan F, Higgins LA, Jelleryd E, Lopez M, Acerini CL. ISPAD Clinical Practice Consensus Guidelines 2018: nutritional management in children and adolescents with diabetes. Pediatr Diabetes. 2018;19(Suppl 27):136-54. https://doi.org/10.1111/ pedi. 12738 .

18. Laffel LM, Limbert C, Phelan H, Virmani A, Wood J, Hofer SE. ISPAD. Clinical Practice Consensus Guidelines 2018: sick day management in children and adolescents with diabetes. Pediatr Diabetes. 2018;19(Suppl 27):193-204. https://doi.org/10.1111/ pedi. 12741 .

19. Board of governors in supersession of the medical council of India. Telemedicine Practice Guidelines. https://www.mohfw.gov.in/pdf/ Telemedicine.pdf accessed on 26 May 2020.

20. Delamater AM, de Wit M, McDarby V, Malik JA, Hilliard ME, Northam E, et al. ISPAD Clinical Practice Consensus Guidelines 2018: psychological care of children and adolescents with type 1 diabetes. Pediatr Diabetes. 2018;19(Suppl 27):237-49. https://doi. org/10.1111/pedi.12736.

Publisher's note Springer Nature remains neutral with regard to jurisdictional claims in published maps and institutional affiliations. 